\title{
"Agolaquena": elementos para uma abordagem de formas complexas de discurso na enunciação de crianças autistas
}

\author{
José Temístocles Ferreira Júnior ${ }^{1}$ \\ Natanael Duarte de Azevedo ${ }^{2}$ \\ Vicentina Ramires Borba ${ }^{3}$
}

Departamento de Letras/Programa de Pós-Graduação em Estudos da Linguagem, Universidade Federal Rural de Pernambuco

Resumo: O objetivo da presente pesquisa é investigar como se organiza a categoria de pessoa nas produções enunciativas da criança autista para vislumbrar a instauração da singularidade do sujeito no exercício da língua. Nosso corpus é formado por dados de interação envolvendo duas crianças autistas diferentes em situações diversas (tanto clínica quanto naturalística), presentes no trabalho de Rêgo Barros (2011). Os resultados de nossas análises mostram que, através da observação dos mecanismos enunciativos presentes na fala da criança autista, é possível compreender diferentes modos de apropriação do sistema da língua e de instauração da singularidade do sujeito no discurso. Nesse sentido, as formas complexas de discurso na enunciação da criança autista têm a propriedade de explicitar, dentro das regularidades que suportam a categoria de pessoa no discurso, as singularidades do estar/ser de cada sujeito na relação discursiva com o outro.

Palavras-chave: Criança autista; Enunciação; Categoria de pessoa; Formas complexas de discurso.

Title: "Agolaquena": Elements for an approach to complex forms of discourse of autistic children's enunciation

Abstract: The aim of this research is to investigate how the category of person is organized in the enunciative productions of the autistic child in order to glimpse the establishment of the subject's singularity in the use of language. Our corpus is formed by interaction data involving two autistic children in different situations (both clinical and naturalistic), present in the work of Rêgo Barros (2011). The results show that, by observing the enunciative mechanisms present in the speech of the autistic child, it is possible to understand different ways of language system appropriation, as well as establishing the singularity of the

\footnotetext{
${ }^{1}$ Doutor em Linguística pela Universidade Federal da Paraíba. É professor adjunto nas áreas de Linguística e Língua Portuguesa da Unidade Acadêmica de Educação a Distância e Tecnologia e professor permanente do Programa de Pós-Graduação em Estudos da Linguagem na Universidade Federal Rural de Pernambuco. Orcid: https://orcid.org/0000-0002-8679-5726. E-mail: josetemistocles@yahoo.com.br.

${ }^{2}$ Doutor em Letras pela Universidade Federal da Paraíba. É professor adjunto da Unidade Acadêmica de Educação a Distância e Tecnologia, professor permanente do Programa de Pós-Graduação em História e coordena do Programa de Pós-Graduação em Estudos da Linguagem na Universidade Federal Rural de Pernambuco. Orcid: http://orcid.org/0000-0003-1435-2923. E-mail: natanael.duarte.ufpb@hotmail.com.

${ }^{3}$ Doutora em Letras pela Universidade Federal de Pernambuco. É professora associada do Departamento de Letras, professora permanente do Programa de Pós-Graduação em História e é vice-coordenadora do Programa de Pós-Graduação em Estudos da Linguagem na Universidade Federal Rural de Pernambuco. Orcid: http://orcid.org/0000-0003-3837-4473. E-mail: vicentinaramires@terra.com.br.
} 
subject in the speech. In this sense, the complex forms of discourse in the enunciation of the autistic child have the property of explaining, within the regularities that support the category of person in discourse, the singularities of being of each subject in the discursive relationship with the other.

Keywords: Autistic child; Enunciation; Category of person; Complex forms of speech.

\section{Considerações iniciais}

Na conclusão do texto "O aparelho formal da enunciação", Benveniste (1989, p. 90) afirma que, a partir do quadro formal esboçado por ele ao examinar o processo enunciativo, "amplas perspectivas se abrem para análise das formas complexas do discurso." A noção de "formas complexas do discurso" não foi exatamente explicitada nem desenvolvida pelo linguista no referido artigo ou em outros textos. O fato é que em "O aparelho formal da enunciação", Benveniste procura analisar elementos subjacentes ao ato de colocação da língua em funcionamento ao mesmo tempo em que sinaliza a possibilidade de um programa para apreensão de fenômenos relativos à linguagem e à enunciação.

No rastro da abertura criada pela perspectiva enunciativa de estudos da linguagem de Benveniste (1988; 1989), buscaremos analisar o modo singular com que a criança autista se apropria da categoria de pessoa e enuncia sua posição no discurso. O ponto de partida de nossa discussão é dado pelo modo singular com que a categoria de pessoa se instaura na enunciação de crianças autistas. A dificuldade ou mesmo a falta de inversão pronominal, amplamente registrada por diversos pesquisadores (KANNER, 1943; RITVO, 1976; TUSTIN, 1984; LAZNIK, 2004; 2011), aliada à fala ecolálica, nos enunciados empregados pela criança autista se apresenta para nós como indício de uma falha perceptível no plano enunciativo, cujas proporções precisam ser dimensionadas. Isso demanda, entretanto, um deslocamento de perspectiva para o exame da singularidade no sintoma, qual seja: o que a falha do sistema pronominal pessoal na fala autística pode dizer sobre a relação entre linguagem e subjetividade? Se há uma flagrante afetação da linguagem nos quadros de autismo, é preciso investigar a natureza que essa afetação representa para o exame da linguagem e para o tratamento da ancoragem subjetiva no autismo.

Com base em uma perspectiva enunciativa, não podemos reduzir a subjetividade ao uso de formas linguísticas preestabelecidas, pois é na enunciação que tais formas são negociadas e construídas. Nesse sentido, partimos da hipótese de que a recorrente ausência de indicadores de pessoalidade na fala da criança autista ou mesmo o uso inapropriado das formas pessoais deixa transparecer um funcionamento linguístico-discursivo implícito à enunciação. O funcionamento de tais operações expõe as relações que a criança estabelece com a linguagem e com o outro a quem dirige seus enunciados, e, a partir dessa premissa, nossa tarefa consiste em buscar compreender as especificidades da organização e da operacionalização da categoria de pessoa na enunciação da criança autista.

O objetivo deste artigo é investigar o modo com que a criança autista marca a categoria de pessoa em sua enunciação e o que está implicado em formas de discurso que, 
como mostraremos, podem ser consideradas complexas. A partir da teoria de Benveniste (1988; 1989) sobre a categoria de pessoa e de seus apontamentos sobre a organização e funcionamento da linguagem, encontramos elementos para subsidiar as especificidades das indicações pessoais na enunciação do sujeito sem se desfazer das regularidades próprias à ordem da língua. Essa perspectiva nos permite compreender as razões que sustentam a realidade do homem na linguagem e a natureza específica do mecanismo de indicação de pessoa na enunciação da criança autista.

Nesse sentido, buscaremos redimensionar as bases lançadas por Benveniste (1988; 1989) para apreensão da natureza dos índices de pessoa na linguagem, tomando como ponto de referência a enunciação da criança autista. Nossas análises estão fundamentadas na leitura que empreendemos da teoria de Benveniste sobre a pessoalidade na linguagem, que nos permite a formulação de alguns princípios para abordagem da categoria de pessoa no ato enunciativo. Tais princípios serão expostos no decorrer deste trabalho e servirão de instrumento para descrição e análise do funcionamento singular da linguagem nas condutas enunciativas da criança autista.

A linguagem prevê um espaço para distinção entre as pessoas discursivas e a nãopessoa. Essa distinção torna-se crucial para organização dos papéis discursivos assumidos no instante do ato enunciativo e revela uma estrutura opositiva e funcional que fundamenta e rege as relações entre as pessoas no processo de enunciação. Iremos retomar os pressupostos que sustentam essa organização para abordar a construção da categoria de pessoa subjacente à fala da criança autista e, ao mesmo tempo, procuraremos compreender de que modo a criança operacionaliza tal categoria e marca sua participação no ato enunciativo.

Sob o aporte teórico que explicitamos acima, iremos analisar fragmentos longitudinais de cenas enunciativas envolvendo crianças autistas diferentes. Nosso corpus é formado por dados de interação de díades variadas em situação clínica presentes no trabalho de Rêgo Barros $(2011)^{4}$. Assim, o corpus a ser investigado aqui é composto por enunciações de duas crianças autistas diferentes. As outras duas crianças foram acompanhadas por Rêgo Barros (2011) e receberam o diagnóstico de um neurologista e de um psiquiatra infantil. Detalharemos os casos a serem apresentados antes de procedermos às análises dos dados.

Com essas considerações, deixamos claro que não iremos fazer um estudo de caso, mas analisaremos dois estudos de caso já publicados, e os fragmentos que iremos apresentar e analisar aqui constituem exemplos ilustrativos que servem de base para reflexão em torno de questões que envolvem autismo e constituição subjetiva. No entanto, afirmar que os fragmentos a serem analisados constituem exemplos ilustrativos não significa dizer que faremos mera aplicação/exemplificação das discussões teóricas levantadas e das categorias de análise construídas às situações observadas. Como veremos, a enunciação infantil,

\footnotetext{
${ }^{4}$ Destacamos que pesquisa apresentada não teve acesso a participantes humanos e buscou abordar exemplos ilustrativos divulgados em Rêgo Barros (2011) em seu trabalho de doutoramento, devidamente referenciado no nosso artigo.
} 
sobretudo aquela marcada pela irregularidade comum às perturbações da linguagem, apresenta-se como uma empiria que perpetuamente interroga os modelos de análises forjados à luz de uma teoria, com pretensões de explicar integralmente e exaurir determinados fenômenos.

As análises que serão feitas aqui têm caráter essencialmente qualitativo e visam reinterpretar as condutas linguageiras da criança autista a partir da observação da organização e do funcionamento da categoria de pessoa. As duas díades foram expostas na pesquisa de Rêgo Barros (2011) e contam com uma criança autista 5 na faixa etária entre 7 e 8 anos e outra criança autista 6 na faixa etária entre 2 e 4 anos, ambas no contexto clínico de interação com uma fonoaudióloga. O corpus de Rêgo Barros (2011) é formado por filmagens e transcrições de cenas de interação entre as crianças autistas e uma fonoaudióloga, neste caso, a própria pesquisadora. Rêgo Barros não desenvolveu estudos de caso, e as cenas apresentadas constituem exemplos ilustrativos das reflexões desenvolvidas ao longo de sua pesquisa.

Rêgo Barros (2011) dispôs os fragmentos observados em quadros, nos quais se alternam a fala da fonoaudióloga e a fala da criança autista, e também fez uma transcrição ortográfica da fala dos participantes das situações observadas e adotou os seguintes critérios para fazer notações em seus registros: a) (incompreensível): para as dúvidas sobre o que fora escutado; b) LETRAS MAIÚSCULAS: para os gritos ou emissões em voz alta; c) - - - - -: para silabação; d) (tempo cronometrado): para intervalo de tempo entre uma fala e outra igual ou superior a 2 segundos; e) Grafemas duplicados: para os prolongamentos na fala.

Os recortes a serem apresentados aqui receberam uma nova numeração (diversa daquela que apresentam em seus lugares de origem), em virtude dos prejuízos que poderiam causar à leitura se mantivéssemos sua numeração original, constante nas teses de onde foram retirados. Além disso, no início de cada recorte, acrescentamos informações genéricas sobre o contexto da cena enunciativa observada e sobre a idade da criança. Diante de qualquer informação adicional, relevante para compreensão do recorte observado, iremos recorrer à utilização de colchetes ou de notas de rodapé.

\section{Princípios para uma abordagem da categoria de pessoa na enunciação da criança autista}

A discussão que Benveniste $(1988 ; 1989)$ faz sobre a categoria de pessoa está inserida em sua abordagem da relação entre referência e enunciação. Se a referência é determinada pelo uso da língua e a significação se presentifica no a priori das relações do signo com os outros signos, há, por outro lado, termos que possuem a particularidade de remeter unicamente às instâncias do discurso em que estão inseridos. Nesse sentido, para Normand (2009), o problema da relação entre referência e enunciação situa a singularidade da

\footnotetext{
${ }^{5}$ Essa criança, que na pesquisa de Rêgo Barros recebe o nome fictício de "Estênio", foi diagnosticada autista por uma neurologista.

${ }^{6}$ Identificado na referida pesquisa pelo nome fictício de "Luciano", o menino recebeu o diagnóstico de autismo por um psiquiatra infantil.
} 
abordagem de Benveniste, pois nele se encontra a preocupação com a descrição de alguns tipos de enunciados com a particularidade de não dissociar sentido e referência, ao mesmo tempo em que instalam na língua o sujeito que nela enuncia. Em outros termos, a suirefencialidade do discurso traz à cena da descrição linguística a relação indissolúvel entre a referência na língua e sua enunciação para compreensão do modo de ser e de funcionar do sentido no uso da língua.

$\mathrm{Na}$ perspectiva benvenistiana, a língua dispõe de formas vazias quanto à referencialidade das quais o locutor se apropria para definir-se a si mesmo como "eu", sujeito da enunciação, e, ao mesmo tempo, instala nas instâncias do discurso o seu interlocutor - o "tu". As formas linguísticas vazias de referência de que fala Benveniste são por ele denominadas "índices/indicadores de subjetividade". Esses indicadores remetem a uma realidade enunciativa e, por isso, devem ser tomados em relação à instância discursiva em que estão inseridos. Com isso, Benveniste se afasta das abordagens pragmáticas que consideram a referência dêitica um indício da remissão que a língua faz ao exterior ou ao contextual e sublinha o caráter sui-referencial dos indicadores de subjetividade, cuja existência está ligada ao ato enunciativo e tem por base o ponto de vista do sujeito que enuncia. É essa sui-referencialidade que nos leva a perceber que o sujeito está na língua e, por essa razão, deve ser pensado em sua enunciação.

Sob a noção de indicadores de subjetividade estão contempladas as categorias que indicam pessoalidade, temporalidade, espacialidade etc., atualizadas por meio de índices/indicadores específicos. Essas categorias estão ligadas ao eixo referencial criado e sustentado pela instância discursiva que as emprega. Todas essas categorias possuem caráter subjetivo e, em consequência, estão submetidas à dimensão intersubjetiva da linguagem. Essa dimensão intersubjetiva determina também o funcionamento conjunto das categorias da linguagem e a consideração dos aspectos correlacionais que as revestem, pois a enunciação de dada categoria implica a mobilização das outras duas e juntas formam o que estamos chamando aqui de "bases enunciativas" da linguagem. Dizemos "bases" porque elas representam o alicerce necessário à constituição e à instituição do sujeito no discurso. É por meio dessas bases que o sujeito se sustenta e encontra sentido para ser.

No interior de cada base enunciativa, é possível perceber a oposição necessária ao funcionamento conjunto e à manutenção da ordem reversível da linguagem. A distinção entre essas categorias decorre do próprio exercício da língua, pois nelas estão situadas as experiências singulares de cada sujeito que se coloca na e pela linguagem por meio das instâncias de discurso mobilizadas no ato enunciativo. É na instância de discurso que a relação eu-tu $\leftrightarrow$ aqui $\leftrightarrow$ agora encontra suas determinações e é essa relação que forma a base axial para constituição do sistema da língua, do qual derivam outras classes linguísticas, como "meu", "teu", "hoje", "amanhã", "neste lugar" etc. Logo, a instância de discurso tenciona os aspectos sociais e individuais, gerais e específicos, regulares e singulares da linguagem, fundamentais à concretização do ato enunciativo. Para que o locutor se diga sujeito, ele deve tornar própria a regularidade subjacente ao sistema da língua que regula e 
fundamenta as relações interpessoais e, ao mesmo tempo, fornece os elementos indispensáveis à representação do sujeito.

Nesse sentido, para abordagem da categoria de pessoa subjacente à enunciação das crianças autistas, a partir da leitura dos textos de Benveniste (1988; 1989), propomos os seguintes princípios norteadores das reflexões que faremos a seguir:

a) a ancoragem subjetiva da criança autista na linguagem está fundamentada na enunciação, que dispõe de bases apropriadas para organização e operacionalização das relações entre os sujeitos. Essas bases estão representadas pelas categorias de espacialidade, temporalidade e pessoalidade, definidas pela instância de discurso que as mobiliza e atualizadas por meio de índices linguísticos específicos;

b) a categoria de pessoa está organizada em duas correlações opositivas: a correlação de pessoalidade e a correlação de subjetividade. Toda referência às pessoas do discurso está integrada ao processo de enunciação;

c) ao tomar a palavra, a criança autista assume as condições impostas pelo ato enunciativo: passa a ser a "pessoa-eu" (pessoa subjetiva) em relação à "pessoa-tu" (não subjetiva) e ambas se opõem à "não-pessoa". A presença da criança autista na linguagem e sua assunção à condição de "pessoa-eu" são efetivadas pela apropriação de um sistema linguístico necessário para o engajamento do locutor na enunciação;

d) o modo de organização da categoria de pessoa no exercício enunciativo comporta elementos da língua como realidade virtual (signos discretos que estão integrados a uma ordem com leis próprias) e elementos do discurso, criados por uma instância enunciativa que pressupõe um quadro de relações intersubjetivas necessárias à efetivação do ato enunciativo. Para assumir a condição de locutor, a criança autista precisa necessariamente se apropriar da língua e se marcar no discurso;

e) por esse último princípio, a organização da categoria de pessoa abre espaço para instauração da singularidade daquele que enuncia na regularidade própria ao sistema da língua. Na enunciação, a especificidade do discurso proposto pelo locutor está condicionada a uma generalidade representada pelo plano semiótico da língua. A criança autista precisa adentrar nesse sistema para enunciar a singularidade de sua posição de locutor na relação discursiva com o outro.

Com base nos princípios formulados, iremos desenvolver as análises dos exemplos ilustrativos a respeito do engajamento da criança autista na enunciação, procurando fazer a exposição de algumas conclusões sobre a singularidade da instauração do sujeito na língua em quadros marcados pelo transtorno autístico.

\section{A criança autista na linguagem: a construção/organização do dispositivo de pessoa}

A enunciação comporta em si mesma os elementos fundamentais à organização da categoria de pessoa que permite ao infans a assunção à posição de locutor e, a partir daí, sua proposição como sujeito. Em outras palavras, no ato enunciativo estão presentes os requisitos necessários para organização da categoria de pessoalidade, essencial para que o 
não falante se torne falante e enuncie com isso sua posição de sujeito. O mecanismo da enunciação é engendrado, de um lado, por um sistema formal e, de outro, pelo exercício discursivo. A posição do locutor e do interlocutor se define em oposição a uma ausência que é instaurada na ordem própria da língua. Em outros termos, a língua comporta a ausência necessária para que a presença dos participantes do discurso seja representada. A criança autista, portanto, adentra nessa lógica a partir da enunciação proposta por um locutor que Ihe atribui o lugar de interlocutor, e ambos se veem representados pela língua no discurso.

Toda esta configuração que se estabelece na categoria de pessoa está submetida a uma instância de discurso presente no ato enunciativo, que faz com que toda referência às pessoas ganhe sentido. Por estar subordinada a uma instância de discurso, a referência às pessoas será sempre única e irrepetível (dada a unicidade da instância discursiva, ligada a condições singulares de pessoa, espaço e tempo) e produzirá, com efeito, sempre novas pessoas. Se, por um lado, a instância de discurso imprime ao ato enunciativo o caráter da unicidade e da irrepetibilidade, por outro, o aspecto da efemeridade cria na enunciação certa instabilidade, pois quando o locutor passa a enunciar se depara com a certeza de que o que está por vir será sempre o novo, o único e o que não se repete.

É justamente neste ponto que devemos considerar o mecanismo da língua: a língua contém a instabilidade própria ao ato enunciativo, por disponibilizar para os participantes desse ato formas vazias de referencialidade que devem ser preenchidas pela instância de discurso que as assume. Logo, as formas linguísticas para indicação das pessoas apresentam certa estabilidade, pois são dadas por um sistema que está acima de qualquer representação particular, e é em direção a esse sistema que o infans se movimenta para a autoindicação de seu papel no discurso.

\section{A criança autista pela linguagem: a operacionalização do dispositivo de pessoa}

Denominamos "operacionalização" o mecanismo enunciativo pelo qual a criança explicita a construção/organização da categoria de pessoa por meio da produção de um enunciado. Nesse caso, para operacionalização do dispositivo do sistema de indicações pessoais, implícito à enunciação, há uma mobilização simultânea entre instâncias de diferentes grandezas, dotadas de especificidades funcionais e organizacionais. Quando a criança entra na lógica do dispositivo de pessoalidade, o movimento pela linguagem irá levála à explicitação dos papéis discursivos. A direção desse movimento é a mobilização das formas linguísticas apropriadas à representação das pessoas do discurso e a transformação dos índices do paradigma linguístico de pessoa em índices efetuados no discurso.

Nesse sentido, segundo Benveniste (1989), para abordar a enunciação no quadro formal de sua realização, devemos considerar: 1ㅇo próprio ato; 2으 as situações em que ele se realiza; 3 o os instrumentos de sua realização. Ao tomar o ato individual de conversão da língua em discurso, Benveniste afirma que ele traz à tona a figura do locutor e as condições de alocução a que todo o processo enunciativo está submetido. Sobre os instrumentos fundamentais à realização do ato enunciativo, Benveniste (1989) assinala que, no processo 
de apropriação da língua, o locutor enuncia sua posição tanto por meio de índices específicos quanto através de procedimentos acessórios.

Mas quais são os índices específicos e os procedimentos acessórios dos quais o locutor necessariamente deve se valer para enunciar sua posição e a posição do seu parceiro enunciativo? Os índices específicos dizem respeito às categorias fundamentais para execução do ato enunciativo (pessoa, tempo e lugar), denominadas por nós de "bases enunciativas da linguagem", e os procedimentos acessórios representam mecanismos de agenciamento por meio dos quais o locutor procede a uma organização sintagmática das formas linguísticas. Além disso, na perspectiva benvenistiana, a enunciação comporta um aparelho de funções por meio do qual os procedimentos acessórios se prestam à realização de grandes funções sintáticas, tais como interrogação (enunciação que suscita uma resposta), intimação (ordens, apelos, pedidos), asserção (comunicação de uma certeza do locutor). Naturalmente, há uma impossibilidade de um trabalho repertoriar exaustivamente os procedimentos acessórios da enunciação, pois infinitas são possibilidades de combinação entre as unidades da língua.

Resta-nos, agora, buscar compreender quais são os modos com que a criança autista, ao se apropriar do aparelho formal da enunciação (a língua), enuncia sua posição de locutor e pessoa subjetiva na relação discursiva com o outro. A conduta linguageira de uma das crianças autistas acompanhadas por Laznik (2011) serve de exemplo para ilustrar essa flutuação:

Tão logo entra na sala, ele [Mourad] corre até o armário de brinquedos, murmurando: "Procurar médico", enquanto tenta alcançar a caixa onde fica o estetoscópio. Ele acompanhou a mãe ao médico. Mourad: Eu te ajudo! - diz ele, embora seus gestos indiquem claramente que quer ser ajudado. Eu [Laznik]: Se tu me disseres me ajuda, eu te ajudo. Mourad: Me ajuda. Passo-Ihe [Laznik] a caixa onde fica o estetoscópio, mas, instantes depois, ele puxa minha manga; perguntoIhe o que quer, ele responde: Subir. Eu [Laznik]: Quem quer subir? Mourad: Mourad, no quarto andar. (...) Instantes mais tarde, como não consegue abrir um leque que tem um fecho meio complicado, ele [Mourad] se irrita e grita: "Eu te ajudo!". Então lhe respondo: "Eu é a pessoa que fala, que faz" (...). (LAZNIK, 2011, p. 120, destaques da autora)

Nessa passagem, a criança autista diz, por duas vezes, "Eu te ajudo" e, ao que parece, tentava se referir à pessoa com quem falava. Nesse caso, embora já reconheça seu lugar de pessoa na relação discursiva com o outro, Mourad esbarrou no caráter reversível dos índices pessoais. A criança não procedeu ao deslocamento necessário à enunciação dos índices que explicitam as bases enunciativas da linguagem. Mas o embaraço no deslocamento referencial necessário à enunciação dos indicadores de pessoa não constitui uma particularidade da criança autista, como mostram Ferreira Júnior (2014) e Ferreira Júnior, Flores e Cavalcante (2015). Na verdade, a reversibilidade dos índices de pessoa se apresenta como um problema para sua explicitação na enunciação infantil. A solução que geralmente as crianças encontram é utilizar os nomes e os nomes próprios para indicação dos lugares de pessoa. Em Ferreira Júnior (2009), foi mostrado que as crianças costumam se representar por meio dos nomes próprios ao invés de utilizar pronomes pessoais ou verbos, talvez buscando estabilizar 
o caráter reversível flagrante nessas classes, mas ainda assim há reversibilidade na classe dos nomes, pois esse traço diz respeito aos papéis enunciativos assumidos pelas pessoas do discurso.

Se a criança autista não instaura sua singularidade subjetiva prioritariamente por meio da explicitação dos índices de pessoa em sua enunciação, como, então, podemos vislumbrar seu processo de apropriação da língua e seu engajamento no ato discursivo? É aí que devemos considerar os procedimentos acessórios através dos quais o locutor também enuncia seu lugar de pessoa na enunciação. Mostramos que esses procedimentos acessórios podem ser realizados por meio de mecanismos de agenciamento, nos quais as unidades linguísticas de determinado sintagma são reorganizadas. A nosso ver, a ecolalia representa um mecanismo de agenciamento efetuado pela criança autista. Por meio da ecolalia, a criança retoma um segmento que é dado pela enunciação de seu parceiro e o insere em sua própria enunciação, fazendo desse segmento um enunciado novo.

Uma das crianças autistas acompanhadas por Rêgo Barros (2011), Estênio, costumava utilizar expressões aparentemente desconexas com a situação enunciativa em que apareciam. Conforme relata Rêgo Barros (2011), nas sessões de terapia fonoaudiológica, Estênio costumava perguntar: "cadê vovô?", "cadê Ana?" (mãe), "cadê Beto?" (pai), "cadê Felipe?" (irmão), "cadê Lícia?" (irmã). Ainda que esses enunciados não mantivessem uma relação clara com a situação em que a criança se encontrava, Rêgo Barros (2011), que exercia o papel de fonoaudióloga de Estênio, procurou indagar a família da criança a respeito das recorrentes expressões em sua fala:

\footnotetext{
Após as entrevistas realizadas com familiares de Estênio para construir a história da sua linguagem, soubemos que era comum à família as frases "cadê vovô?", "cadê Ana?" (mãe), "cadê Beto?" (pai), "cadê Felipe?" (irmão), "cadê Lícia (irmã)?" em uma espécie de jogo de linguagem, em que os sujeitos se escondem do campo visual infantil e após o questionamento surgem. Somada a isso, costumeiramente, a mãe da criança durante os afazeres domésticos questionava sobre a localização de Estênio e de seus irmãos quando esses estavam fora de seu campo visual, como meio de informação sobre a situação de segurança que as crianças ocupavam dentro do domicílio. (RÊGO BARROS, 2011, p. 89)
}

De posse dessas informações, a terapeuta ressignificou a fala ecolálica de Estênio e procurou entrar no seu jogo dialógico, dirigindo à criança a mesma pergunta contida em sua fala ecolálica. Se todo enunciado é sempre um novo enunciado, ao retomar o discurso do outro, a criança autista faz dele um mecanismo de apropriação e de sustentação na relação com o outro: é novo que se repete, e nesse ato de retomada há sempre algo na ecolalia não consegue reproduzir, deixando à mostra locutor que dela faz uso. Vejamos a situação:

Recorte 01 - Idade: 7 anos

Contexto: Estênio está em sessão de terapia com a fonoaudióloga. A criança brinca com as peças de um jogo de encaixe. 
Estênio

1) O sapo não lava o pé, não lava

Porque não quer ele mora lá na

2) lagoa não lava o pé porque não quer, mas que chulé

3) Eu vi o sapo

Na beira do rio de camisa verde

4) morrendo de frio frio frio. Não era o sapo nem perereca

era Nando só de cueca eca eca. O sapo não lava o pé não lava

5) porque não quer ele mora lá na lagoa não (3s) porque não quer, mas que chu posso guardar?

6)

7) Posso guardar? (...)

8)

9)

O sapo não lava o pé não lava porque não quer ${ }^{7}$
Isabela

Porque não quer ele mora lá na lagoa não lava o pé porque não quer, mas que chulé

\section{A criança faz o} encadeamento com outra canção.

Na beira do rio de camisa verde morrendo de frio frio frio. Não era o sapo nem perereca
Mais uma vez a fonoaudióloga acompanha.

Estênio apresenta a ecolalia "posso guardar?"

Tu queres guardar de novo?

Tu pode falar, tu pode

brincar...

Pode, você pode fazer o que quiser. Queres fazer uma linha? Faz uma linha.

Hoje tás a fim de fazer linha não, né?

Rêgo Barros (2011, p. 117), ao rever os registros da filmagem da sessão e intrigada com a insistência de Estênio para cantar o mesmo trecho da canção infantil "O sapo não lava o pé, não lava porque não quer", cogitou a possibilidade de haver outro sentido sob esse segmento:

Figura 1 - Associação entre significantes

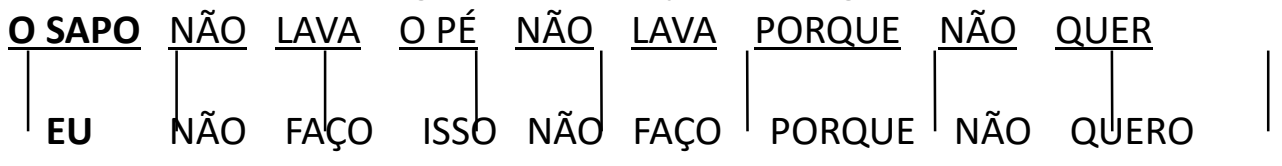

A associação é bem possível, só não temos recursos para precisá-la aqui. Já dissemos que há certa flutuação referencial na enunciação, decorrente, sobretudo, da relação nem

\footnotetext{
${ }^{7}$ Os negritos são da autora.
} 
sempre coincidente entre forma e sentido na língua. Logo, há possibilidade de a criança querer dizer algo diferente do que, de fato, disse. Mas não é sobre o "querer dizer" que nos debruçamos aqui; é sobre o que a criança "disse". Chama a nossa atenção a ecolalia (agora reconhecida pela autora - ver observações sobre a cena, no turno 05) "Posso guardar?" que aparece no turno 07 e no final do turno 05, quando subverte a aparente linearidade da canção entoada pela criança. Nas descrições feitas durante o acompanhamento clínico, a fonoaudióloga observa que a criança sempre costuma brincar com um jogo de peças ao mesmo tempo em que cantava a referida música:

\footnotetext{
Durante as sessões fonoaudiológicas, Estênio constantemente apresentava a canção "o sapo não lava o pé" de maneira ecolálica. Seus movimentos ritualísticos diante dos objetos da sala eram sempre os mesmos: sentava-se em frente à mesa infantil, derrubava uma caixa com peças de um jogo de encaixe, enchia as mãos em concha com as peças e as soltava delicadamente como se fora areia que escapa entre os dedos. Em seguida, iniciava a canção "o sapo não lava o pé". Ao seu término, encadeava a canção "eu vi o sapo" e recomeçava a cantoria repetidas vezes, acompanhada da atividade de juntar as peças do jogo de encaixe. (RÊGO BARROS, 2011, p. 115-116)
}

No turno 05 do recorte 01, é visível que Estênio, após aglutinar duas músicas infantis, interrompe inesperadamente sua canção para introduzir nela a referida fala ecolálica. A fonoaudióloga tenta questioná-lo quanto ao seu desejo de querer guardar, mas a criança insiste com a ecolalia "Posso guardar?" no turno 07, sem retomar os enunciados que sua terapeuta acaba de proferir. Não seria esse um indício de que a função da ecolalia era indicar, nessa situação, o fim da música? E se, nas condutas dialógicas da criança, o fim da música estiver associado ao início do jogo com as peças de encaixe, como bem sublinhou Rêgo Barros (2011), não estaria a criança autista buscando assinalar, por meio da ecolalia, sua vontade de brincar com o jogo?

A bem da verdade, não dispomos de recursos para testar tais hipóteses, mas sabemos que nada comparece ao discurso ao acaso e que, por meio da ecolalia, a criança autista recupera algo repetível da enunciação e o faz novo. Ainda que haja certa impossibilidade de afirmação de um sentido unívoco e diretivo para qualquer enunciado, o princípio enunciativo que acabamos de relembrar não pode ser negado. Qual seja: do ponto de vista enunciativo, há algo de repetível na enunciação da ecolalia e algo de irrepetível que se instaura nas circunstâncias singulares do processo enunciativo. Se a criança insiste na retomada de uma fala, é porque busca instaurar, a partir de uma estrutura linguística repetível, novos sentidos na relação discursiva com o outro, e isso lhe é garantido pelas condições próprias à enunciação.

Outra operação linguístico-discursiva que não pode passar despercebida é a associação que a criança faz entre as canções "O sapo não lava o pé" e "Eu vi o sapo". Não se trata de uma associação aleatória. As duas músicas versam sobre o mesmo tema. Perceber essa relação a partir da identificação do conteúdo das canções e fazer a fusão entre as melodias demanda da criança, por um lado, ancoragem subjetiva para apreensão das 
semelhanças que existem entre as letras das canções e, por outro, uma operação que incide sobre as estruturas linguísticas e sobre a relação discursiva com o outro. Enquanto entoava a música "O sapo não lava o pé", a criança era acompanhada na melodia por sua terapeuta, mas ao término dessa canção a criança faz emergir no discurso a possibilidade de uma associação (não perceptível à primeira vista) e cria, com isso, uma fissura no discurso da terapeuta, que, por um instante, interrompe a melodia (turno 03) e dá continuidade no turno seguinte.

Estamos diante, portanto, de uma operação enunciativa realizada pela criança autista quando assume a posição de locutor: apropriando-se do aparelho da enunciação, a criança deixa à mostra uma operação que se assemelha a um enjambement poético ${ }^{8}$, fazendo da segunda canção uma extensão da primeira e emparelhando ambas no mesmo turno de fala. Tal operação veicula outro procedimento de agenciamento de formas linguísticas por meio do qual a criança locutora procede à combinação de canções diferentes que, no entanto, abordam o mesmo assunto. Assim, seguindo o critério da identidade de conteúdos, a criança autista funde as formas linguísticas em uma mesma entoada.

Além desses procedimentos, identificamos três outras operações de agenciamento realizadas pelas crianças autistas. As duas primeiras foram observadas na fala da mesma criança que acabamos de mostrar. Nelas, é possível verificar os procedimentos de recombinação e ajuste da fala do outro. Vejamos a situação que consta nos fatos mostrados por Rêgo Barros (2011, p. 97-98):

Recorte 02 - Idade: 7 anos.

Contexto ${ }^{9}$ : Ao final de uma sessão fonoaudiológica, a terapeuta solicita a ajuda de Estênio para guardar os materiais usados em terapia.

Estênio

1)

2) $\hat{E} \hat{E} \hat{E}$.

3)
Isabela

Vamos guardar esse assim, dentro da caixa. (5s) Me ajuda.

Obrigada. Me dá outro.

Não. Me ajuda primeiro a guardar. Me ajuda a guardar. Obrigada. Junta pra mim os animais.

\section{Cena}

Fonoaudióloga e criança estão encerrando as atividades de mais uma sessão. Estênio entrega a terapeuta uma peça do jogo "o pequeno construtor".

Estênio interrompe e depois retorna a atividade.

\footnotetext{
${ }^{8}$ De acordo com Goldstein (1986, p. 76), o termo "enjambement" diz respeito a uma construção sintática especial que liga um verso poético ao seguinte buscando a complementação do sentido.

${ }^{9} \mathrm{~A}$ numeração no quadro indica os turnos de fala dos participantes da cena enunciativa.
} 
"Agolaquena": elementos para uma abordagem de formas complexas de discurso na enunciação de crianças autistas

4) $\hat{E} \hat{E} \hat{E} \hat{E}$. O sapo não lava o pé não lava porque

5)

6) $\hat{E} \hat{E} E \hat{E} \hat{E} \hat{E}$ a gola que na ${ }^{10}$

7)
José Temístocles Ferreira Júnior Natanael Duarte de Azevedo Vicentina Ramires Borba

A criança canta acompanhada de batidas ritmadas na mesa com uma peça do jogo.

Destacamos que entre os animais que a criança recolhe não há sapo. São cavalo, vaca, galinha e pato.

não quer ele mora lá na lagoa não lava o pé porque não quer.

Ah! Traz pra mim os animais agora.

Conforme aponta Rêgo Barros (2011), era comum essa criança entoar a canção infantil "O sapo não lava o pé" e, ao ver os animais sobre a mesa (entre os quais não havia uma peça para representar a figura de um sapo), a criança começa a cantar a referida música. No turno 04, ao dizer "ÊÊ̂ÊÊ. O sapo não lava o pé não lava porque", Estênio tem seu turno tomado pela terapeuta, que complementa a melodia com a parte restante da música. No turno 06, a criança enuncia uma sequência estranha e aparentemente sem qualquer sentido, que passa despercebida aos ouvidos da terapeuta: "ÊÊÊÊ̂E a gola que na". O enunciado se inicia pela mesma sequência sonora "Ê̂ÊÊÊ" usada pela criança para introduzir a canção (turno 04), mas o inusitado se instaura na combinação seguinte: "a gola que na".

Ao rever os dados de sua filmagem, Rêgo Barros (2011) percebeu que a expressão "a gola que na", que aparece na fala de Estênio, continha os mesmos elementos integrantes do sintagma "Lá na lagoa", da canção que a criança entoara, e propôs o seguinte esquema descritivo:

Figura 2 - Representação do mecanismo de agenciamento linguístico

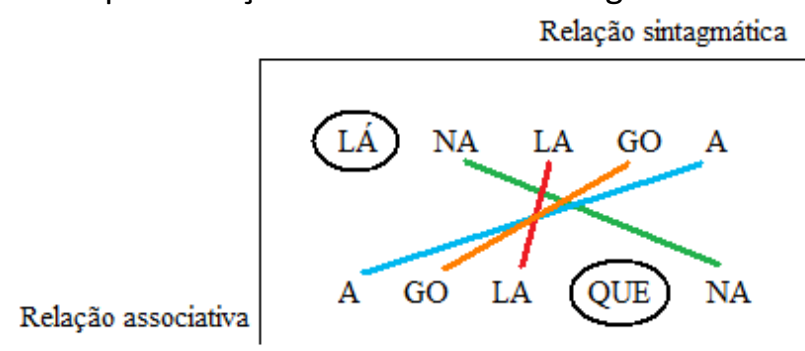

(Figura 12)

Fonte: Rêgo Barros (2011, p. 98)

Trata-se de uma operação de agenciamento, procedimento acessório que se volta à sintagmatização dos signos linguísticos por meio do qual o locutor enuncia sua posição na relação discursiva. Na verdade, há aí duas operações de agenciamente no segmento "a gola que na". A primeira é instituída pelo novo arranjo que a criança faz para recombinar as unidades que compõem a expressão "Lá na lagoa". No novo arranjo, preservam-se todos os

\footnotetext{
${ }^{10}$ Os negritos são da autora.
} 
elementos da expressão original, mas há outra alteração: a criança demonstra perceber que ao recombinar as unidades do sintagma, o segmento "lá" aparece no início do enunciado "Lá na lagoa" e se repete no início da palavra "lagoa", o que a obrigaria a redundá-lo dizendo "a gola lana". É aí que notamos outro mecanismo de agenciamento, por meio do qual a criança introduz o pronome relativo "que", vocábulo que na língua portuguesa é um dos principais responsáveis pelo mecanismo de relativização sintática.

Ora, tanto no mecanismo de recombinação, quanto na relativização sintática, a criança deixa à mostra seu engajamento no circuito da enunciação. As operações de agenciamento constituem, como já destacamos, procedimentos acessórios pelos quais o locutor enuncia sua posição de sujeito. O que faz a criança autista nessa passagem senão enunciar/instituir sua singularidade subjetiva na língua? Se os índices específicos que representam a categoria de pessoa não são explicitados em seu discurso, a criança autista encontra na língua outros modos para enunciar a singularidade de seu lugar na relação discursiva. O recurso à sintagmatização com a natureza do fenômeno apresentado acima constitui uma forma complexa de discurso através da qual a criança sinaliza um lugar enunciativo. É preciso, portanto, compreender a relação discursiva na qual a criança está inserida para vislumbrar sua posição de sujeito.

Benveniste (1989, p. 87) afirma que "o que em geral caracteriza a enunciação é a acentuação da relação discursiva com o parceiro, seja este real ou imaginado, individual ou coletivo." (itálicos do autor). Por esses termos, a compreensão dos modos de engajamento da criança autista na enunciação deve necessariamente considerar sua relação discursiva com seu(s) parceiro(s). Assim, voltamo-nos para um outro mecanismo de agenciamento verificado na fala de Luciano, criança autista acompanhada por Rêgo Barros (2011). De acordo com a autora, Luciano começou a enunciar a palavra "bibi" repetidas vezes, fato que a fez conversar com a mãe da criança. Passemos ao relato do caso acompanhado pela terapeuta:

\begin{abstract}
Em consulta fonoaudiológica, a mãe de Luciano, revela que a criança passou a falar constantemente e aleatoriamente a palavra "bibi". Ela mesma encontra o sentido de mãe nesse termo, pois é pelo nome "bibi" que seus familiares a reconhecem. Posteriormente, sob orientação, a família passou a relacionar o nome bibi à figura materna e ao nome mamãe, passando a criança a usar a palavra "mamã". Alguns meses seguintes, a mãe mostra-se frustrada porque a criança deixa de usar a palavra mamã e fala "mimi". A mãe não percebeu, no entanto, que a criança realizou uma nova combinação de signos linguísticos caracterizada pela junção das palavras bibi e mamã, saindo de uma posição estática na língua caracterizada por repetições aleatórias de palavras, para efetuar uma circulação entre os eixos sintagmático e associativo. (RÊGO BARROS, 2011, p. 100).
\end{abstract}

$\mathrm{Na}$ análise que desenvolve sobre o assunto, Rêgo Barros (2011) aponta os movimentos significantes que ocorrem sob o eixo sintagmático e destaca a aglutinação de palavras na fala de Luciano: “(bibi + mamã $=$ mimi) resultou na criação de um neologismo e representou a saída da criança autista de uma posição de fixidez no eixo sintagmático." (RÊGO BARROS, 2011, p. 101). 
A nosso ver, a fusão entre as formas linguísticas citadas demonstra outro mecanismo de agenciamento por meio do qual a criança autista recombina as unidades integrantes dos nomes "bibi" e "mamã" para chegar a um terceiro termo, que só ela utiliza na enunciação: "mimi". Logo, essa operação singulariza na língua o modo com que a criança representa o lugar da mãe e, ao mesmo tempo, singulariza o lugar da criança. Ao que parece, o termo "bibi" é frequentemente empregado em seu contexto familiar para fazer referência à mãe. Por sua vez, o termo "mamã" resultou da associação que os familiares fizeram, sob a orientação da fonoaudióloga, para mostrar à criança o lugar da mãe. Ao propor para a mãe um terceiro termo, a criança deixa entrever não só sua apreensão do lugar discursivo ocupado pelo outro (crucial para a definição de sua posição como pessoa subjetiva), mas seu modo de ser sujeito pela língua.

É aí que encontramos as pistas para atingir os modos de instauração da subjetividade da criança autista no discurso: não é pela acentuação dos índices específicos de pessoalidade, que permanecem implicados em sua enunciação; é pelos procedimentos acessórios, efetivados nos mecanismos de agenciamento das formas linguísticas. Em outras palavras, para a criança autista o mecanismo de agenciamento das formas linguísticas não representa um procedimento acessório, pois é a partir dele que a criança assinala a singularidade de seu lugar de pessoa na enunciação e é por meio dele que a criança deixa transparecer sua apropriação do sistema da língua. Logo, na fala da criança autista, o agenciamento das formas linguísticas constitui um índice específico para marcação de seu engajamento na enunciação e para instauração de sua singularidade subjetiva, enquanto que os índices específicos de pessoalidade assumem o papel de procedimento acessório, pois, embora se façam presentes, não é especificamente por meio deles que a criança autista marca seu lugar de pessoa.

Na cena a seguir, é possível perceber a emergência de pronomes pessoais na fala da mesma criança autista que acabamos de mostrar. Vejamos a passagem apresentada por Rêgo Barros (2011):

Recorte 03 - Idade: 7 anos.

Contexto ${ }^{11}$ : A criança e a fonoaudióloga conversam durante a sessão de terapia.

Estênio

1)

Eu dô dô, meu Deus.

2)

3) EE: eu sou seu Deus.
Isabela

A criança não olha

para a

fonoaudióloga.

Estênio olha rapidamente para a terapeuta e desvia o olhar em seguida.

Cena

Você é seu Deus? 
4) Posso posso guardar? (2s)

5)

Não. (2s)

6) iiii: AAAAAAAA:

Embora Rêgo Barros (2011), ao analisar o recorte acima, não tenha descartado a possibilidade de haver ecolalia no discurso que a criança emprega no turno 01 ("Eu dô dô, meu Deus") - dada a inserção dessa criança nas práticas religiosas que integram seu cotidiano familiar, é possível observar que no turno 03, ao ser questionado pela terapeuta que pergunta "Você é seu Deus?", Estênio responde: “EE: eu sou seu Deus.". Ora, nesse fragmento, fica evidente que a criança procede a um deslocamento no plano das formas linguísticas que enuncia. A terapeuta utiliza os índices pessoais "você é" e a criança diz "eu sou". É notório o deslizamento entre as marcas linguísticas formais do discurso decorrente da reversibilidade que caracteriza a relação entre as pessoas da enunciação.

Todas essas passagens parecem explicitar o modo singular com que a criança autista enuncia sua posição no espaço da relação discursiva que estabelece com a terapeuta. No episódio relatado por Laznik (2011), exposto por nós mais acima, a interlocutora da criança consegue perceber que, embora os elementos linguísticos do enunciado tenham a aparência de uma asserção, o ato praticado pela criança constitui uma intimação. Logo, através do arranjo enunciativo da língua, por meio de um procedimento acessório, a criança autista dá relevo à sua intenção e busca influenciar sua interlocutora, o que evidencia o recurso a um mecanismo de sintagmatização do qual a criança autista se vale para indicar sua posição discursiva.

Se não é possível apreender de modo unívoco e constante todos os fenômenos enunciativos que comparecem à fala da criança, sabemos, no entanto, que nada que se apresenta na enunciação funciona de maneira aleatória, indiferente às determinações discursivas impostas pelo exercício enunciativo da língua. Todo enunciado constitui um fragmento discursivo que integra o processo de enunciação. A complexidade das formas discursivas observadas assinala a deflagração de um modo singular de enunciação. Assim, a partir da observação do funcionamento da categoria de pessoa através de formas complexas de discurso na enunciação da criança autista, temos uma nova dimensão da tese benvenistiana segundo a qual o fundamento da subjetividade está no exercício da língua (BENVENISTE, 1988), pois é no próprio processo de enunciação que o sujeito marca a sua singularidade, no ato de conversão da língua em discurso.

\section{Considerações finais}

Os apontamentos que fizemos nas seções anteriores nos conduzem ao caráter singular do "estar/ser" do homem na linguagem. O funcionamento da enunciação comporta a regularidade da língua e a singularidade de cada discurso. É singular o modo com que o 
locutor enuncia sua posição de sujeito na relação com o outro. Esse é o ponto para onde convergem as reflexões em torno da enunciação e do caráter intersubjetivo que funda a realidade do sujeito na língua. Toda a realidade do homem é propiciada na/pela linguagem, e inúmeros acarretamentos são gerados por esse fato. Sob o ângulo da categoria de pessoa, base fundante para instituição do sujeito na língua, o infans ascende à posição de locutor ao ocupar um espaço na instância de discurso que assume. Essa ocupação está condicionada pela intersubjetividade (presente na linguagem) que determina os propósitos do ato de enunciar e instaura o sujeito no circuito da enunciação.

Por um lado, o ato enunciativo pressupõe a existência de bases ligadas a uma dada instância de discurso e, por outro, a instância de discurso necessita de um sistema de formas vazias de referência para que seja possível a comunicação entre sujeitos. Em outras palavras, deve haver espaço para instauração da singularidade subjetiva na regularidade das relações entre sujeitos. Para atingir esse fim, a enunciação comporta a presença de um sistema formal que, a um só tempo, está acima de qualquer indicação de um indivíduo em particular (o que inviabilizaria a comunicação intersubjetiva) e serve (paradoxalmente) à singularidade de cada pessoa que assume esse sistema em determinada instância discursiva. Todos os elementos de que necessita um não falante para se tornar locutor e sujeito no/do discurso estão presentes no ato enunciativo.

Do ponto de vista enunciativo, afirmamos há muitas maneiras para a criança autista enunciar sua posição de sujeito na língua, mas para isso ela deve se apropriar de um lugar na linguagem a partir da relação discursiva que estabelece com o outro. Ao proceder à ocupação das bases enunciativas da linguagem (processo fundamental para que a criança venha a compreender a enunciação proposta pelo outro e dirija a este uma enunciação de retorno), a criança autista torna flagrante a construção/organização do dispositivo de pessoa. Esse movimento é inteiramente regular no processo enunciativo, pois sem ele o indivíduo não pode compreender ou falar o que quer que seja. Mas como é possível afirmar que a criança autista ocupou um lugar nas bases enunciativas da linguagem? Nos casos que apresentamos aqui (além dos exemplos que constam na literatura especializada - os próprios registros de Kanner (1943)), todas as crianças enunciaram algo (balbucios, algaravias, ecolalias, nomes próprios etc.) em algum momento de interação com adultos.

Após ocupar um espaço na estrutura enunciativa da linguagem, a criança autista enuncia sua posição de locutora (o que pressupõe uma relação discursiva com um parceiro enunciativo) não por meio de marcas formais que explicitem os índices específicos de sua enunciação, mas por meio de procedimentos acessórios, atualizados em formas complexas de discurso. Isso ficou claro quando vimos os processos de agenciamento tanto na fala de Estênio quanto na fala de Luciano. No momento em que Estênio reorganiza as unidades que compõem o sintagma "lá na lagoa" (da música infantil "O sapo não lava o pé") e enuncia "a gola que na", torna-se evidente a proposição de um novo arranjo que preserva as unidades do segmento original. No interior desse novo arranjo, fica visível outro processo de agenciamento, por do meio qual a criança autista introduz o mecanismo de relativização sintática: ao recombinar as unidades do sintagma "lá na lagoa", a criança percebe a repetição 
da unidade "lá", presente tanto no início do segmento, quanto no início da palavra "lagoa". A solução que encontra para fazer um ajuste é introduzir o pronome relativo "que" para fazer a relativização sintática.

$\mathrm{Na}$ fala de Luciano, o agenciamento se deu de outra maneira: a partir da fusão entre as unidades componentes dos nomes "bibi" e "mamã", nomes que representam o lugar de pessoa ocupado pela mãe da criança. O resultado do processo de recombinação das unidades linguísticas desses nomes gerou uma forma nova "mimi", com a qual a criança deixou transparecer um mecanismo de sintagmatização e de apropriação do sistema da língua.

Em outros termos, na enunciação das crianças autistas apresentadas aqui, a singularidade do engajamento do locutor é instituída, na língua, por meio de procedimentos acessórios (visíveis nos mecanismos de agenciamento que analisamos) e não pela explicitação dos índices específicos de seu papel de pessoa na relação discursiva. E isso diz muito: a criança autista experimenta a realidade de "estar/ser" sujeito no e por meio do discurso ao ocupar as bases enunciativas da linguagem e esse processo é inteiramente regular, pois a criança precisa das bases para se inserir na relação discursiva com o outro. Os reflexos da singularidade de seu movimento de ocupação na estrutura enunciativa são vistos quando a criança autista passa a enunciar sua posição na língua, o que pode ser feito tanto pelo mecanismo de explicitação dos índices de pessoa subjacentes à sua fala, quanto por meio de procedimentos acessórios. Ao fazer uso desses últimos, a criança autista singulariza seu estar/ser sujeito na língua e no discurso. Logo, o funcionamento da categoria de pessoa na enunciação da criança autista é singularizado pelo mecanismo de agenciamento das formas linguísticas.

A categoria de pessoa figura como primeiro ponto para revelação da subjetividade na linguagem. Ao assumir o papel de locutor, a criança autista assume também a categoria de pessoa e o aparelho formal que a organiza. Quando enuncia, a criança autista (locutor) diz "pessoa subjetiva" na relação com a "pessoa não-subjetiva", diz categoria de pessoa, diz a apropriação de um sistema formal para organização dos índices pessoais, diz "eu" e "tu". Mas existem diferentes modos para explicitação dessas relações e, nesse sentido, a singularidade do engajamento da criança autista no discurso é marcada por procedimentos de reorganização das unidades linguísticas, procedimentos apreensíveis no quadro figurativo das relações linguístico-discursivas, nas quais se inserem as produções enunciativas da criança.

A criança autista traz à tona os índices de sua singularidade subjetiva por meio de procedimentos acessórios, que, na fala da criança autista, assumem estatuto de índices específicos. Por sua vez, os índices específicos de pessoa (pronomes, verbos, nomes) assumem um papel de procedimento acessório na enunciação da criança autista, pois, embora compareçam à fala da criança, esses índices são relegados a um segundo plano para marcação de sua posição de locutor. Em todo caso, trata-se de um recurso encontrado pela criança autista que observamos para explicitar o processo de apropriação do aparelho formal da enunciação e, ao mesmo tempo, marcar sua singularidade no exercício da língua. Eis, 
então, o ponto crucial para apreensão da singularidade subjetiva da criança autista: o exercício enunciativo da língua. Considerar esse fato implica reconhecer a necessidade de investigação das relações discursivas em que se insere a criança autista para compreensão dos mecanismos dos quais se vale para indicação da categoria de pessoa.

\section{Referências}

BENVENISTE, É. Problemas de linguística geral I. Tradução de Maria da Glória Novak e Maria Luisa Neri. Campinas, São Paulo: Pontes, 1988.

BENVENISTE, É. Problemas de linguística geral II. Tradução de Eduardo Guimarães et al. Campinas, São Paulo: Pontes, 1989.

FERREIRA JÚNIOR, J. T. 2009. A dêixis pessoal nas interações mãe-bebê: a constituição do sujeito no processo de enunciação. 2009. 91 f. Dissertação de mestrado em Linguística. João Pessoa - PB: Universidade Federal da Paraíba.

FERREIRA JÚNIOR, J. T. 2014. A criança autista na/pela linguagem: da categoria de pessoa à singularidade do sujeito no processo de enunciação. 2014. 178 f. Tese de doutorado em Linguística. João Pessoa - PB: Universidade Federal da Paraíba.

FERREIRA JÚNIOR, J. T.; FLORES, V. do N.; CAVALCANTE, M. C. B. A teoria de Benveniste sobre a pessoalidade e seus desdobramentos na enunciação infantil. Revista Delta, v. 31, n. 2, p. 527-558, 2015. https://doi.org/10.1590/0102-44509841905164449

GOLDSTEIN, N. Versos, sons, ritmos. São Paulo: Ática, 1986.

KANNER, L. Os distúrbios autísticos do contato afetivo. In: ROCHA, P. S. (Org.). Autismos. São Paulo: Editora Escuta, 1997[1943]. p. 111-170.

LAZNIK, M. C. A voz da sereia. Tradução de Cláudia Fernandes Rohenkol et al. Salvador: Ágalma, 2004.

LAZNIK, M. C. Rumo à fala: três crianças autistas em Psicanálise. Tradução de Procópio Abreu. Rio de Janeiro: Companhia de Freud, 2011.

NORMAND, C. Convite à linguística. São Paulo: Editora Contexto, 2009.

RÊGO BARROS, I. B. Da linguagem e sua relação com o autismo: um estudo linguístico saussureano e benvenistiano sobre a posição do autista na linguagem. 2011. 135 f. Tese (Doutorado em Letras). Programa de Pós-Graduação em Letras, Universidade Federal da Paraíba, João Pessoa, 2011.

RITVO, E. R. Autism: diagnosis, current research and management. New York: Spectrum, 1976. TUSTIN, F. Autistic shapes. International Review Psycho-Analysis, v. 11, p. 279-290, 1984. 